\title{
Special Issue: International Conference on Value Chain Sustainability ICOVACS 2010, Valencia (Spain)
}

\author{
Carlos Andrés-Romano \\ Polytechnic University of Valencia (SPAIN) \\ candres@,omp.upv.es
}

\section{Introduction}

This special issue of the Journal of Industrial Engineering and Management is focused on new trends in sustainable development and corporate social responsibility strategies in the 21st Century Global Market.

As it is well known, one of the Millennium Development Goals that United Nations members have agreed to achieve by the year 2015 is to ensure environmental sustainability. This means to meet human needs while preserving the environment so these needs can be met not only in the present, but also for generations to come. One way to achieve this goal is to convince private organizations to involve themselves in sustainable supply chains and deep social corporative practices.

From the academics' point of view, this topic provides a wide field where industrial engineers, managers, advanced technology experts, sociologists, information systems experts, psychologists, financial experts and so on, can help. Most of the problem related with sustainability needs multidisciplinary approaches from engineering, manufacturing/services, marketing, computers, economics, ethics, etc, and it is necessary to provide synergic solutions based in the previous experience in traditional supply chain problems.

This was one of the ideas for starting the International Conference on Value Chain Sustainability series, to bring academic, industry and government personnel from various countries to present and discuss the next frontier for product design, branding and logistics from sustainable and social responsible point of view as a leadership strategy in a global market. 
The first ICOVACS conference was held in Izmir, Turkey in 2008 with the theme "Integrating Design, Logistics and Branding for Sustainable Value Creation. ICOVACS 2009 was held in Louisville, Kentucky with the theme "Product Design, Branding and Logistics as a Leadership Strategy in a Global Market". This special issue selects some of the papers presented at ICOVACS 2010 which took place at Valencia, Spain with the theme "Towards a Sustainable Development and Corporate Social Responsibility Strategies in the 21st Century Global Market".

This Special Issue summarizes some of the best contributions presented at ICOVACS 2010. We wish to thank all the contributing authors and in particular all the reviewers whose valuable comments have improved substantially the quality of this Special Issue.

\section{Overview of the papers}

The papers selected to this special issue are of high quality and they are organized as follows.

The first paper by Jairo R. Coronado-Hernández, Eliana Pardo and María ValeroHerrero presents an example of how the Micro, Small and Medium enterprises (SMEs) play an important role for economic growth. The authors apply a multiobjective mathematical model to know what is the best choice to select development projects in a job generation environment subject to legal status and budgetary constraints.

The second paper by Ignacio Eguia, Sebastian Lozano, Jesus Racero and Fernando Guerrero shows a procedure to design reconfigurable disassembly systems. These systems will play a key role in the future of recycling processes. The authors use a two-step methodology where products are first grouped into families and then families are sequenced through the RDS, computing the required machines and modules configuration for each family. The optimal sequence of the product families is calculated using a Mixed-Integer Linear Programming model minimizing reconfigurability and operational costs. This methodology is validated with an illustrative example.

The third paper by Cristóbal Miralles, Raymond Holt, Juan A. Marin-Garcia and Lourdes Canos-Daros presents a case study demonstrating the use of the PokaYoke approach in a sheltered work centre for disabled. They highlight how PokaYoke tools served to improve accessibility to work by fulfilling Universal Design principles. The real application of this approach both in sheltered work centers and 
ordinary companies can contribute to improve the high unemployment rates of disabled people.

In the fourth paper by Paulina Golinska and Arkadiusz Kawa, a framework for management of reverse flow of materials in automotive industry is presented. The authors identified the main problems that appear within remanufacturing system and use an agent technology to simulate the problem in a dynamic way. This approach takes into account materials and information flow of the recovery network and let the remanufacturing activities to be planned.

The fifth paper by Juan A. Marin-Garcia, Cristobal Miralles, Julio J. Garcia-Sabater and M. Rosario Perello-Marin identifies an extensive set of alternative practices to mass production. They analyze the classification of practices in categories (Flow, TQM, TPM, Customer Relations, Supplier Relations and Human Resources Practices) and identify four constructs with significant effects on the human key performance indicators (job satisfaction, knowledge, integration into ordinary companies and personal and social adjustment).

In the sixth paper by Jalal Ashayeri and Gülfem Tuzkaya the concept of classical location models is extended to include the demand return uncertainties and demand driven characteristics of high-tech return centers. The authors give us an overview of existing literature and present a fuzzy multi-objective location model, showing its complexities and propose an integrated AHP-weighted max-min solution approach. The proposed model can assist managing the dynamics of early or late return surge and supply of return centers, while target service time is maintained, returned centers' capacities are balanced, and the total costs are minimized.

This seventh paper by Ernest Benedito and Albert Corominas studies a production system with reverse logistics such that new and recovered products are indistinguishable, manufacturing and storage capacities are limited, demand is stochastic with time independent probability distribution and where product returns depend on previous sales. With these assumptions, the optimal manufacturing and storage capacities are hard to calculate, mainly because of the relation between sales and returns. In order to improve the tractability of the problem, the authors use linear programming and simulation to analyze if the independence assumption affects the optimal capacities depending on the manufacturing and holding costs.

The eighth paper by Sandra Klute and Robert Refflinghau proposes a generic multidimensional model to structure customer's requirements. The model gives 
feedback of the extent of requirements' fulfillment by measuring the weighted level of performance and the customer satisfaction. The developed generic structuring model fulfils several purposes. It allows surveying and structuring the requirements made on the reference object for further use, which is necessary to transform them into adequate product features. The model also serves to check if all stakeholder requirements have been surveyed or if there are informational deficits. This allows improving or rather structuring the gathering of requirements. And finally, the model offers assistance for matching "new" requirements to adequate dimensions and categories.

The last paper is presented by Esther Álvarez and Alberto de la Calle. It focuses on the so-called last-mile logistics or urban freight distribution in a Spanish town. In particular, it proposes some practices that try to balance two points of view: environmental sustainability and customer service. The paper gives son insights about the variables that have an adverse affect on urban freight distribution.

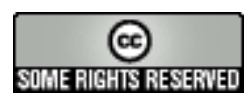

Article's contents are provided on a Attribution-Non Commercial 3.0 Creative commons license. Readers are allowed to copy, distribute and communicate article's contents, provided the author's and Journal of Industrial Engineering and Management's names are included. It must not be used for commercial purposes. To see the complete license contents, please visit http://creativecommons.org/licenses/by-nc/3.0/. 